\title{
Effect of Strain and Temperature on the Yielding of Copper and Nickel
}

\author{
by J. H. Frye, Jr., J. L. Scott, and J. W. Woods
}

$T^{1}$ HERE are at least two effects of temperature on the stress required to produce plastic flow. 1) Metals plastically strained for the same amount at different temperatures possess different stress-strain curves and different internal structures (e.g., nature and density of imperfections). 2) There is both experimental and theoretical evidence that the stress necessary to produce plastic flow may vary with temperature even though the internal structure remains constant..$^{1-5}$ Much of the data in the literature is difficult to interpret because these two effects are simultaneously present. In the work reported here, they are considered separately.

Standard 0.505 in. tensile specimens were prepared from high-purity Mond nickel and OFHC copper. Nickel specimens were annealed in hydrogen at $1150^{\circ} \mathrm{C}$ for $30 \mathrm{~min}$ and furnace cooled. This produced an average grain diameter of $1.4 \mathrm{~mm}$. Copper specimens were annealed in vacuum at $525^{\circ} \mathrm{C}$ for $6 \mathrm{hr}$ and furnace cooled. This produced an average grain diameter of $0.11 \mathrm{~mm}$. Nickel tensile specimens were prestrained in tension at $500^{\circ} \mathrm{K}$, whereas copper tensile specimens were prestrained in tension at room temperature. All specimens were cooled to $74^{\circ} \mathrm{K}$ and heated to room temperature. After these treatments all of the tensile specimens of a given set possessed identical structures.

All specimens were returned to the tensile machine and tested at various temperatures and constant cross-head speed. Many of the tensile curves showed well defined yields but, in order to minimize personal judgment, the yield was always chosen as the stress corresponding to 0.2 pet plastic deformation.

Results are summarized in the graph of yield vs temperature of test, Fig. 1. All of the specimens corresponding to any one line have had identical treatments and, therefore, have identical internal structures. Thus, each line gives the relation between yield stress and temperature for one constant internal structure. The lowest line, which is for annealed nickel, shows no measurable variation of yield with temperature. This is similar to Blewitt's ${ }^{\mathrm{e}}$ results on copper single crystals, but a variation in yield with temperature was found by Andrade and Henderson ${ }^{7}$ in single crystals of nickel, and by Carrecker and $\mathrm{Hibbard}^{8}$ in annealed polycrystalline copper. The three other lines, which are for prestrained materials, show that there is a linear relation between yield stress and temperature when the internal structure remains constant.

Such a relation might be expected from a rate equation such as that of Kauzmann ${ }^{1}$ on the assump-

J. H. FRYE, JR., Member AIME, J. L. SCOTT, Associate Member AIME, and J. W. WOODS are associated with Metallurgy Div., Oak Ridge National Laboratory, Oak Ridge, Tenn.

TN 384E. Manuscript, Dec. 1, 1955.

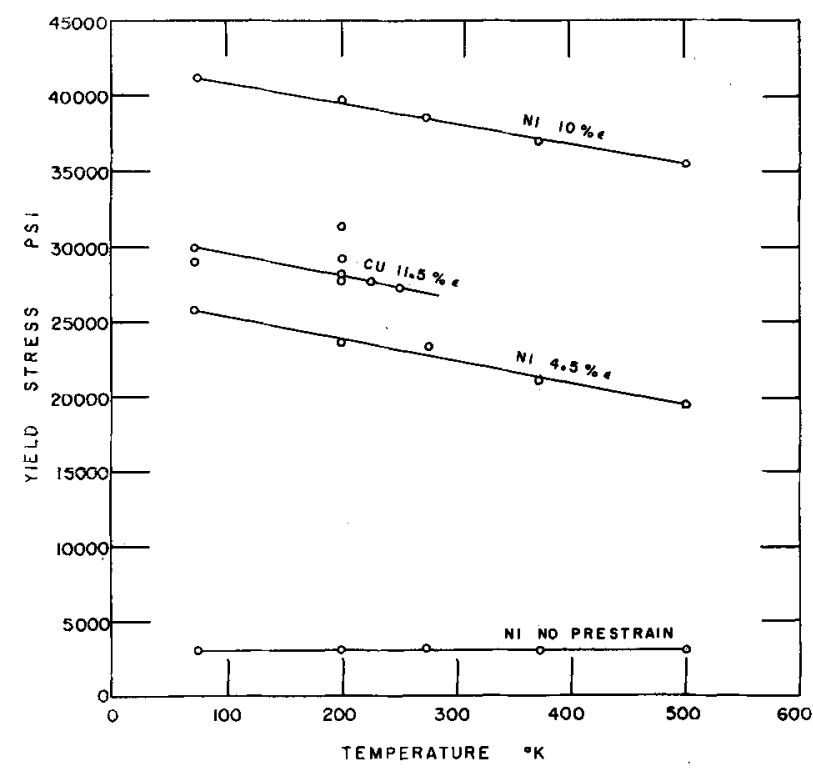

Fig. 1-Flow stress vs temperature for annealed and prestrained Mond nickel and copper. Percentages refer to plastic elongation by tension.

tion that the activation energy is either independent of or linear with temperature. These results would also be expected if the shear moduli of copper and nickel are linear functions of temperature for, as Cottrell and Stokes have pointed out, ${ }^{5}$ in all dislocation theories of strength the flow stress appears proportional to the shear modulus of the material. In copper and nickel, since the modulus of elasticity decreases roughly linearly with increase in temperature, ${ }^{9}$ it is probable that the modulus of shear also decreases approximately linearly with increasing temperature. A detailed discussion of the effect of these and other factors on the temperature dependence of flow stress in face-centered-cubic metals has recently been given by Seeger."

\section{References}

${ }^{1} \mathrm{~W}$. Kauzmann: Flow of Solid Metals from the Standpoint of the Chemical-rate Theory. AIME Trans., 1941, vol. 143, p. 57

2 J. E. Dorn, A. Goldberg, and T. E. Tietz: The Effect of Thermalmechanical History on the Strain Hardening of Metals. AIME Trans., 1949, vol. 180, p. 205.

${ }^{3}$ M. A. Adams and A. H. Cottrell: Effect of Temperature on the Flow Stress of Work-Hardened Copper Crystals. Phitosophicat Magazine, 1955, vol, 46, p. 1187.

4. Seeger: The Generation of Lattice Defects by Moving Dislocations, and its Application to the Temperature Dependence of vol. 46,0 . 1194 .

5. 46, p. 1194. I A. H. Cottrell and R. J. Stokes: Effects of temperature on the 1955, vol. A233, No. 1192, p. 17 . and $78^{\circ} \mathrm{K}$. Physical Review, 1953, vol. 91, p. 1115 .

${ }_{\tau} \mathrm{E}$. N. da C. Andrade and C. Henderson: The Mechanical Behaviour of Single Crystals of Certain Face-Centred Cubic Metals. Philosophical Transactions, 1951, vol: A244, p. 177.

8 R. P. Carreker, Jr. and W. R. Hibbard, Jr.: Tensile Deformation of High-Purity Copper as a Function of Temperature, Strain Rate, and Grain Size. Acta Metallurgica, 1953, vol. 1, p. 654 .

W. Koster: Die 'Temperaturabhangigkeit des Elastigitatsmoduls reiner Metalle. Ztsch. für Metallkunde, 1948, vol. 39, p. 1. 